\title{
COGNITIVE-AFFECTIVE MODEL OF ACCEPTANCE OF MOBILE PHONE ADVERTISING
}

\section{Cristina Olarte-Pascual, Jorge Pelegrín-Borondo, Eva Reinares-Lara}

\section{Introduction}

There are high expectations for mobile phone marketing (Yang, Kim, \& Yoo, 2013). Four trends in particular contribute to the medium's marketing potential worldwide: (1) the significant growth in the use of mobile devices (Khalifa \& Shen, 2008); (2) the forecasts of considerable growth in mobile advertising (MMA Mobile Marketing Association, 2012) compared to the predicted steady decline in spending on conventional media (Infoadex, 2014); (3) the development of increasingly sophisticated mobile devices (Miguel-Dávila, López, \& De Pablos-Heredero, 2012), which has opened up new avenues and formats for marketing communication with consumers; and (4) the strong results achieved by companies with mobile marketing campaigns. In various European markets, such as the United Kingdom, Spain and Italy, these campaigns have registered response rates of up to $47 \%$ among their target audience (IAB Spain Research, 2012).

However, there is a barrier to success: getting users to agree to receive marketing actions on their mobile phones. Field studies on this topic, known as permission-based mobile marketing, are increasingly numerous and representative (Bamba \& Barnes, 2007; Barwise \& Strong, 2002; Carroll, Barnes, \& Scornavacca, 2005; Jayawardhena, Kuckertz, Karjaluoto, \& Kautonen, 2009), as are studies on the adoption of mobile technology (LópezNicolás, Molina-Castillo, \& Bouwman, 2008) and its use as a medium for advertising communication (Lee, Tsai, \& Jih, 2006). However, the literature on the factors that determine attitudes towards and/or intention to receive mobile advertising, and on the relationships between attitude, intention and behaviour, remains minimal and contradictory (Choi, Hwang, \& McMillan, 2008; Okazaki, Katsukura, \& Nishiyama, 2007; Tsang, Ho, \&
Liang, 2004; Xu, 2006; Xu, Liao, \& Li, 2008). Moreover, while the benefits of considering both cognitive and affective factors in order to better understand peoples' appraisals have been widely recognized in the literature (Levav \& McGraw, 2009; van Waterschoot, Kumar Sinha, Van Kenhove, \& De Wulf, 2008; Zielke, 2011), it is not yet known how these factors combine to influence attitudes towards mobile advertising and, thus, the intention to receive it. In this context, the first aim of this paper is to fill these gaps.

Additionally, the literature has recognized the influence of reference groups on people's attitudes, intentions and behaviour (Bagozzi, 2000; Fishbein \& Ajzen, 1975). With regard to mobile marketing communications, authors such as (Bauer, Barnes, Reichardt, \& Neumann, 2005), (Muk \& Babin, 2006) and (Rohm \& Sultan, 2006) have shown that reference groups can positively influence the intention to participate in mobile marketing. However, the literature has not determined how these reference groups moderate cognitive and affective factors in the formation of attitudes. The second aim of this paper is thus to answer that question.

In light of these limitations identified in the literature, we have proposed a model to meet the stated aims. The results show the advisability of treating attitudes towards mobile advertising as a two-dimensional variable including both cognitive factors (ease of use and perceived usefulness) and affective ones (positive and negative emotions). The research also shows how social influence (reference groups) moderates the effect of emotions on behaviour and how the reference group's opinion can increase the gap between attitude and behavioural intention.

The paper is divided into three parts. The first section, which focuses on the theory, 
reviews the literature in order to propose the research hypotheses and the conceptual model to be tested. The second section reports on an empirical study carried out according to the proposed research methodology. Finally, the third section presents the conclusions and discusses the implications for management taking into account certain limitations.

\section{Background and Hypotheses of the Cognitive-Affective Model of Acceptance of Mobile Advertising}

As noted, both cognitive and affective factors influence subjects' appraisals (Dean, Raats, \& Shepherd, 2008). Affect and cognition take place through an interlocked dual system that comes together in natural human behaviour (Boehner, DePaula, Dourish, \& Sengers, 2007).

In the context of mobile communications, few studies have taken a holistic approach to these interrelated factors. Instead, most research has sought to assess only one of these dimensions, usually, the cognitive one. From a joint cognitive-affective perspective, the theoretical background underlying the assumptions of the model for attitudes towards mobile advertising includes both eminently cognitive variables, such as ease of use and perceived usefulness (Karjaluoto, Lehto, Leppäniemi, \& Jayawardhena, 2008; SoroaKoury \& Yang, 2010), and eminently affective ones, such as positive and negative emotions (Kolsaker \& Drakatos, 2009).

\subsection{Ease of Use and Perceived Usefulness}

To identify the determining factors for the acceptance of mobile advertising, (Zhang \& Mao, 2008) proposed a modified technology acceptance model (TAM) based on Davis's TAM (1989) and the theory of reasoned action. This model examines, among other key factors, the influence of usefulness and perceived ease of use on the intention to engage with advertising. The conceptual model validated by Karjaluoto et al. (2008) Lehto, Leppäniemi, showed how perceived ease of use and, in particular, perceived usefulness are both factors that positively influence attitudes towards mobile advertising. However, subsequently, SoroaKoury and Yang (2010), using the extended technology acceptance model (TAM2), studied a sample of 343 university students who engaged with advertising text messages and found that perceived usefulness predicted attitude towards mobile advertising, while perceived ease of use did not.

Based on the contradictory findings in the literature, we proposed testing the following hypotheses:

H1: Perceived ease of use of mobile phones positively affects attitudes towards receiving mobile advertising.

H2: The perceived usefulness of the mobile advertising received positively affects attitudes towards it.

\subsection{Emotions}

Although emotion has been defined in many different ways (Cohen, Pham, \& Andrade, 2008; Scherer, 2005), according to the theory of components, certain shared minimum features make it possible to delimit the concept as a whole (Russell, 2003; Scherer, 2001): need for a stimulus, attribution of the cause of the stimulus, cognitive appraisal, physiological reactions, feeling of pleasure-displeasure, unique qualitative feeling, characteristic action tendencies, and short-term processes.

The literature shows that some emotions trigger action, while others cause individuals to become inhibited or change (O'Neill \& Lambert, 2001; White \& Yu, 2005). In general, objects that cause positive emotions are assessed favourably, while those that cause negative emotions are assessed unfavourably (Bagozzi, Gopinath, \& Nyer, 1999; Mano, 2004). People are naturally inclined to make decisions that minimize the probability of experiencing negative emotions (Lerner, Han, \& Keltner, 2007; Schwarz, 2000).

In the field of mobile communications, research has focussed on the emotional attachment users feel towards their devices (Vincent, 2005). (Kolsaker \& Drakatos, 2009) showed that only users with a strong emotional attachment to their devices are receptive to and perceive greater potential benefits in mobile advertising. With regard to the role of emotions, in a study of 48 students, (Park \& Salvendy, 2012) found that the positive emotions 'desire' and 'affection' are positively correlated with attitudes towards mobile advertising, while the negative emotional dimensions of 'stress' and 'apathy' are negatively correlated. Tsang et al. (2004) and Xu (2006) showed that 'entertainment' positively influenced attitude, 
while Tsang et al. (2004) moreover found that 'irritation' negatively influenced it.

Based on the above findings, we proposed the following hypotheses:

H3: Positive emotions towards mobile advertising positively affect attitudes towards it.

H4: Negative emotions towards mobile advertising negatively affect attitudes towards it.

\subsection{Relationship between Attitude and Intention}

The intention to receive messages is defined as a person's willingness to receive marketing communications on his or her mobile phone. Previous studies have considered the attitude variable to be a determinant of mobile phone users' behaviour and intentions to accept mobile advertising. Tsang et al. (2004) found a direct relationship between attitudes towards mobile advertising, the incentives offered and intentions and behaviour. The model in Lee et al. (2006) shows that favourable attitudes towards mobile advertising that correlate with strong motives lead to greater intentions and positive actions. In a survey of 300 university students, Soroa-Koury and Yang (2010) found that attitudes towards mobile advertising were predictive of the intention to accept/adopt the advertising. Likewise, in a study in China, Xu (2006) found a direct relationship between consumers' attitudes and intentions.

In light of this empirical background, we proposed the following hypothesis:

H5: Positive attitudes towards mobile advertising positively affect the intention to receive it.

\subsection{Subjective Norm: Normative Reference Groups}

The influence of the subjective norm can be defined based on what consumers believe other people might think about a given behaviour. Gauging the influence of reference groups, Peter and Olson (2005) identified two reference groups that contribute to the influence of the subjective norm: (1) normative groups, such as parents and peers (Fitzgerald \& Arndt, 2002), and (2) comparative ones, such as idols (Childers \& Rao, 1992).

The theory of reasoned action (TRA) model (Fishbein \& Ajzen, 1975), as well as its extension in the theory of planned behaviour (TPB) model (Ajzen, 1991), and the TAM2 model (Venkatesh
\& Davis, 2000) provide the rationale for linking the subjective norm to behaviour towards mobile advertising. Knowing how audiences are affected by the subjective norm - more specifically, by the normative reference group (NRG) due to the daily use of mobile devices - as a moderating variable can help to explain mobile advertising acceptance. In this context, the results of the model proposed by Zhang and Mao (2008) confirmed the influence of the subjective norm (Bagozzi, 2000) on the intention to engage with mobile advertising. With similar aims in terms of understanding social influence and how consumers respond to mobile advertising, SoroaKoury and Yang (2010) likewise confirmed the influence of the social norm on attitudes towards mobile advertising as expressed by perceived usefulness. Also useful for the formulation of the proposed model were the findings of $\mathrm{Lu}$ et al. (2005) and López et al. (2008) on the influence of social norms on attitude and intentions to adopt mobile innovations and the confirmed positive influence of the subjective norm on the perceived ease of use and perceived usefulness thereof.

Based on these results, this paper seeks to further explore the moderating role exerted by the NRG on cognitive and affective dimensions of the attitude towards mobile advertising, as well as the moderating effect of this attitude on the intention to receive mobile advertising. Given the small volume of literature on this moderating effect, it was incorporated through the following propositions:

P1: The NRG plays a moderating role in the positive relationship between the perceived ease of use of mobile advertising and attitudes towards it.

P2: The NRG plays a moderating role in the positive relationship between the perceived usefulness of mobile advertising and attitudes towards it.

P3: The NRG plays a moderating role in the positive relationship between positive emotions towards mobile advertising and attitudes towards it.

P4: The NRG plays a moderating role in the negative relationship between negative emotions towards mobile advertising and attitudes towards it.

P5: The NRG plays a moderating role in the positive relationship between attitudes towards mobile advertising and the intention to receive it.

The proposed hypotheses and propositions make up an integrative theoretical model of the 


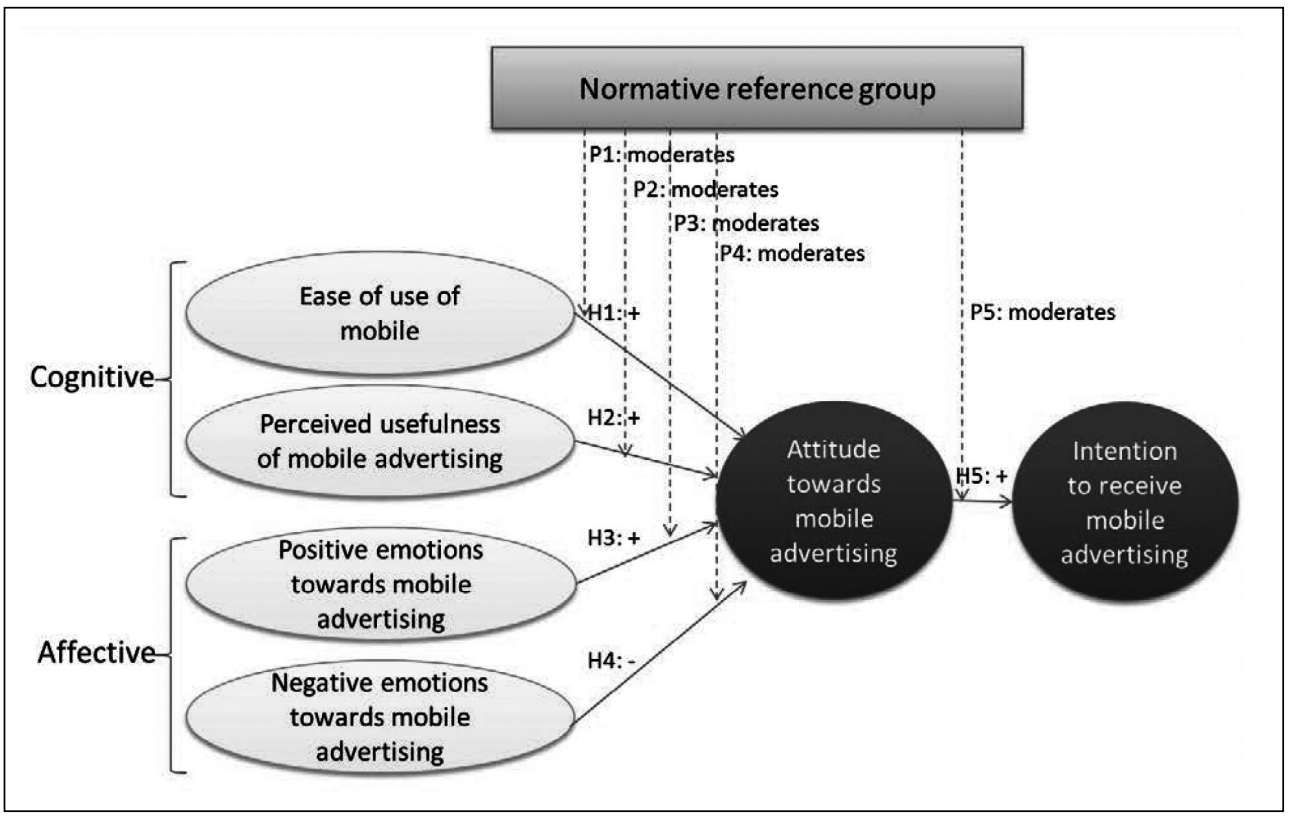

Source: own

variables influencing attitudes and intentions with regard to mobile advertising (Fig. 1).

\section{Research Methodology 2.1 Methodology}

To test the working hypotheses, a sequential process was followed (Fig. 2). In the first phase, given that cognition and emotion come together in human behaviour, we developed a cognitive-affective scale (Tab. 1) that includes both perceived usefulness and ease of use and the positive and negative emotions generated by mobile advertising. Confirmatory factor analysis was used to test its structure, reliability and validity. In the second phase, we used structural equation modelling to test the model's hypotheses. In the third phase, to study the moderating effect of the reference group (the model's propositions), we used sequential cluster analysis to generate groups of individuals based on their NRG. This gave rise to two groups, independent and influenced, on which we then conducted a multi-sample analysis.

\subsection{Description of the Sample and Measurement of Variables}

The data was obtained in two steps: (1) randomized 9,000 sending invitations with a response rate of $26 \%$ and (2) select only individuals receiving mobile advertising by taking into account the structure of the Spanish population by gender and age. The sample was of 612 individuals who were representative of the Spanish adult population and received advertising on their mobile phones. $92.3 \%$ of the sample had been using a mobile phone for more than 5 years, and $35.9 \%$ had more than one mobile.

Table 1 shows how the research variables were measured on five-point Likert-type scales. Two consecutive rounds of pre-testing were conducted to verify proper comprehension of the questionnaire and the adaptation thereof to the aims of the research. 


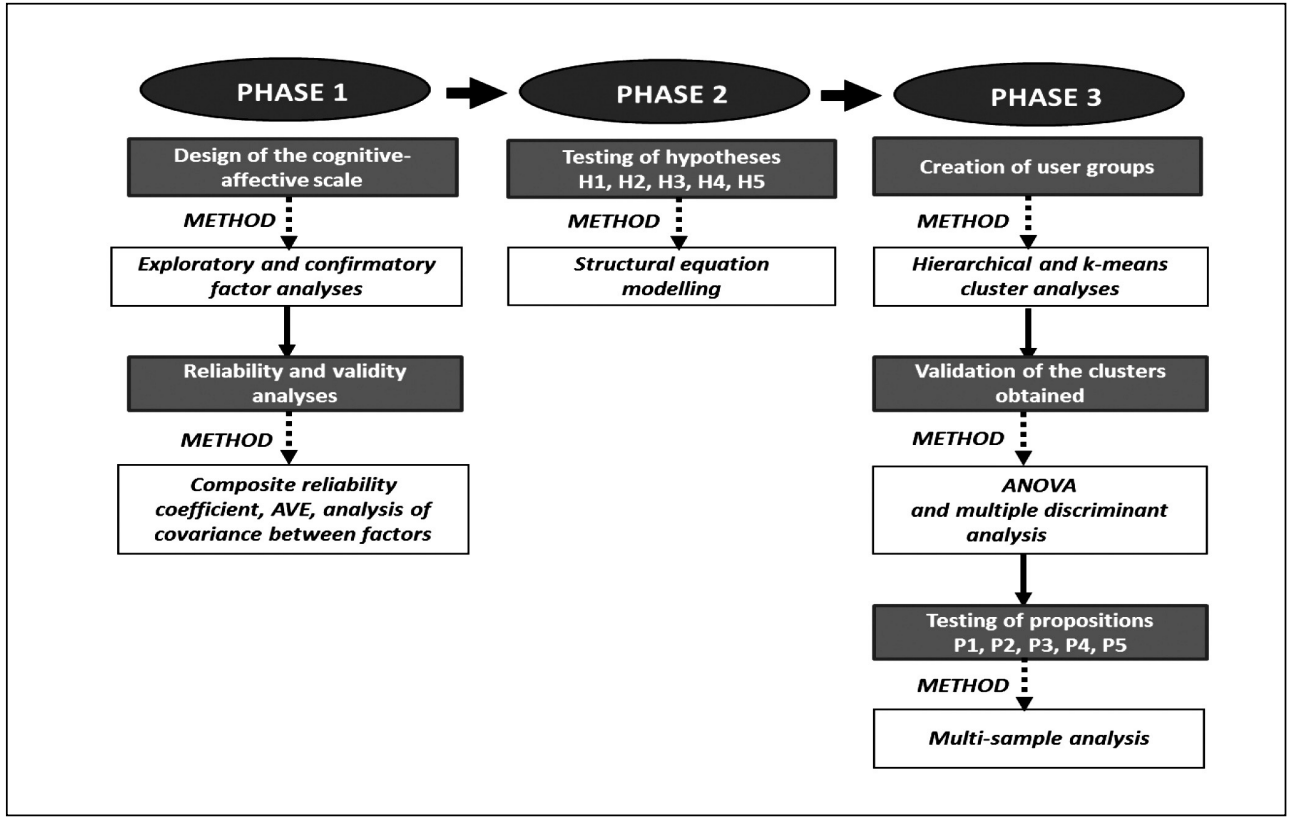

\section{Analysis of Results}

The goodness-of-fit results for the confirmatory factor analysis were satisfactory: $\mathrm{BBNFI}=0.96$; $\mathrm{BBNNFI}=0.96 ; \mathrm{CFI}=0.97$; robust $\mathrm{CFI}=0.96$; $\mathrm{GFI}=0.93 ; \mathrm{AGFI}=0.90 ;$ and $\mathrm{RMSEA}=0.07$. With regard to convergent validity, Table 2 shows that the indicators converged in the assigned factors, as the standardized lambda parameters were significant and greater than 0.5 (Anderson \& Gerbing, 1988). It moreover shows that the average variance extracted (AVE) was greater than 0.5 for all four factor (Hair, Anderson, Tatham, \& Blanck, 1999), and that the composite reliability coefficient was over 0.7 (MacKenzie, Podsakoff, \& Jarvis, 2005), higher than the 0.6 recommended by Bagozzi and Yi (1988).

With regard to discriminant validity, Table 3 shows that the factors are different from each other. The confidence interval around the absolute value of the covariance does not include 1. There is thus no problem of covariance among the factors involved, and the discriminant validity requirement is met.
In the second phase, we used structural equation modelling to test the hypotheses (Fig. 3). The results showed a good fit and the acceptance of all five hypotheses. To reach the confirmatory factor analysis solution, a number of modifications were made. We applied the Lagrange multiplier test (LM test) and the Wald statistic, which evaluates the effect of releasing (or not) a set of parameters simultaneously (Hair et al., 1999). We then considered the convergence of the parameters in the factors to respecify the model (Anderson \& Gerbing, 1988). In our case, we considered it appropriate to eliminate the parameters that contributed little to the factor to which they belonged (lambda $<0.6)$. 
EMOTIONS TOWARDS MOBILE PHONE ADVERTISING

EMO1. I feel that it is nice

EMO2. I feel that it is interesting

EMO3. I feel that it is entertaining

EMO4. I feel that it is interactive

EMO5. I feel that it is convincing

EMO6. I feel that it is credible

EMO7. I feel that it is motivating

EMO8. I feel that it is irritating

EMO9. I feel that it influences me

EMO10. I feel that it is misleading

EMO11. I feel that it is persuasive

\section{PERCEIVED USEFULNESS OF MOBILE ADVERTISING}

PU1. The immediacy of the message makes mobile advertising more useful

PU2. The fact that mobile advertising can be accessed whenever you want makes it more useful

PU3. The fact that mobile advertising can be accessed wherever you want makes it more useful

MOBILE'S EASE OF USE

\begin{tabular}{l} 
EOU1. It is easy for me to use a mobile phone \\
\hline EOU2. I learn how to use new mobile services quickly \\
\hline EOU3. I know what services I can use on my mobile phone \\
EOU4. It is easy for me to access mobile services \\
NORMATIVE REFERENCE GROUP \\
NRG1. I receive mobile advertising because my friends do \\
\hline NRG2. I open mobile advertising because my friends do \\
\hline NRG3. I discuss the advertising sent to my phone with my friends \\
\hline NRG4. The people I care about think I should receive mobile \\
advertising
\end{tabular}

Soroa-Koury and Yang (2010).

Xu (2006/2007); Park et al. (2008); Tsang et al. (2004); Park and Salvendy (2012).

Dodds et al. (1991); Woodruff (1997); Zeithaml (1998); Grewal et al. (1998); Sweeney and Soutar (2001).

Childers and Rao (1992); Peter and Olson (2005); Bagozzi (2000); Fitzgerald and Arndt (2002); Bauer et al. (2005); Rohm and Sultan (2006); Muk and Babin (2006).

\section{ATTITUDE TOWARDS MOBILE ADVERTISING}

ATT. In general, I like mobile advertising

Tsang et al. (2004); Soroa-Koury and Yang (2010).

INTENTION

INT. Intention to receive mobile advertising

Choi et al. (2008), Tsang et al. (2004).

Note: Items shown in italics were removed during the streamlining process. 


\section{Marketing a obchod}

\section{Tab. 2:}

\section{Convergent validity and reliability analysis}

\begin{tabular}{|c|c|c|c|}
\hline Construct/dimension and indicator & $\begin{array}{c}\text { Standardized } \\
\text { parameters } \\
>0.5 \text { and } \\
\text { t-value }>1.96\end{array}$ & $\begin{array}{l}\text { Composite } \\
\text { reliability } \\
\text { coefficient }>0.7\end{array}$ & $\begin{array}{c}\text { Average } \\
\text { variance } \\
\text { extracted } \\
(\mathrm{AVE})>0.5\end{array}$ \\
\hline \multicolumn{2}{|l|}{ F1. Positive emotions (Reflective) } & 0.95 & 0.72 \\
\hline I feel that it is motivating & $0.88(27.4)$ & & \\
\hline I feel that it is entertaining & $0.87(26.7)$ & & \\
\hline I feel that it is convincing & $0.87(27.0)$ & & \\
\hline I feel that it is credible & $0.85(25.6)$ & & \\
\hline I feel that it influences me & $0.75(21.6)$ & & \\
\hline I feel that it is interesting & $0.88(27.3)$ & & \\
\hline I feel that it is nice & $0.87(27.0)$ & & \\
\hline I feel that it is interactive & $0.79(23.2)$ & & \\
\hline \multicolumn{2}{|l|}{ F2. Negative emotions (Reflective) } & 0.73 & 0.58 \\
\hline I feel that it is misleading & $0.90(28.1)$ & & \\
\hline I feel that it is irritating & $0.60(14.9)$ & & \\
\hline \multicolumn{2}{|c|}{ F3. Ease of receiving mobile advertising (Reflective) } & 0.85 & 0.59 \\
\hline I learn to use mobiles quickly & $0.81(22.4)$ & & \\
\hline I know what services I can use & $0.85(24.1)$ & & \\
\hline My mobile is easy to use & $0.61(15.2)$ & & \\
\hline Accessing services on my mobile is easy & $0.77(20.9)$ & & \\
\hline \multicolumn{2}{|l|}{ F4. Perceived usefulness (Reflective) } & 0.91 & 0.77 \\
\hline Useful because of when it is received & $0.93(29.3)$ & & \\
\hline Useful because of where it is received & $0.90(28.1)$ & & \\
\hline $\begin{array}{l}\text { Useful because of the message's } \\
\text { immediacy }\end{array}$ & $0.80(23.3)$ & & \\
\hline
\end{tabular}

\section{Tab. 3: Discriminant validity analysis}

\begin{tabular}{c|r|r|r|r|c}
$\begin{array}{c}\text { Factors } \\
\text { involved }\end{array}$ & Covariance & \multicolumn{1}{c|}{$\begin{array}{c}\text { Standard } \\
\text { error }\end{array}$} & \multicolumn{2}{|c|}{ Confidence interval } & Out-of-range value \\
\hline F1-F2 & -0.292 & 0.055 & -0.402 & -0.182 & 1 \\
\hline F1-F3 & 0.586 & 0.031 & 0.524 & 0.648 & 1 \\
\hline F1-F4 & 0.322 & 0.039 & 0.244 & 0.400 & 1 \\
\hline F2-F3 & -0.183 & 0.052 & -0.287 & -0.079 & 1 \\
\hline F2-F4 & -0.100 & 0.049 & -0.198 & -0.002 & 1 \\
\hline F3-F4 & 0.359 & 0.045 & 0.269 & 0.449 & 1 \\
\hline
\end{tabular}




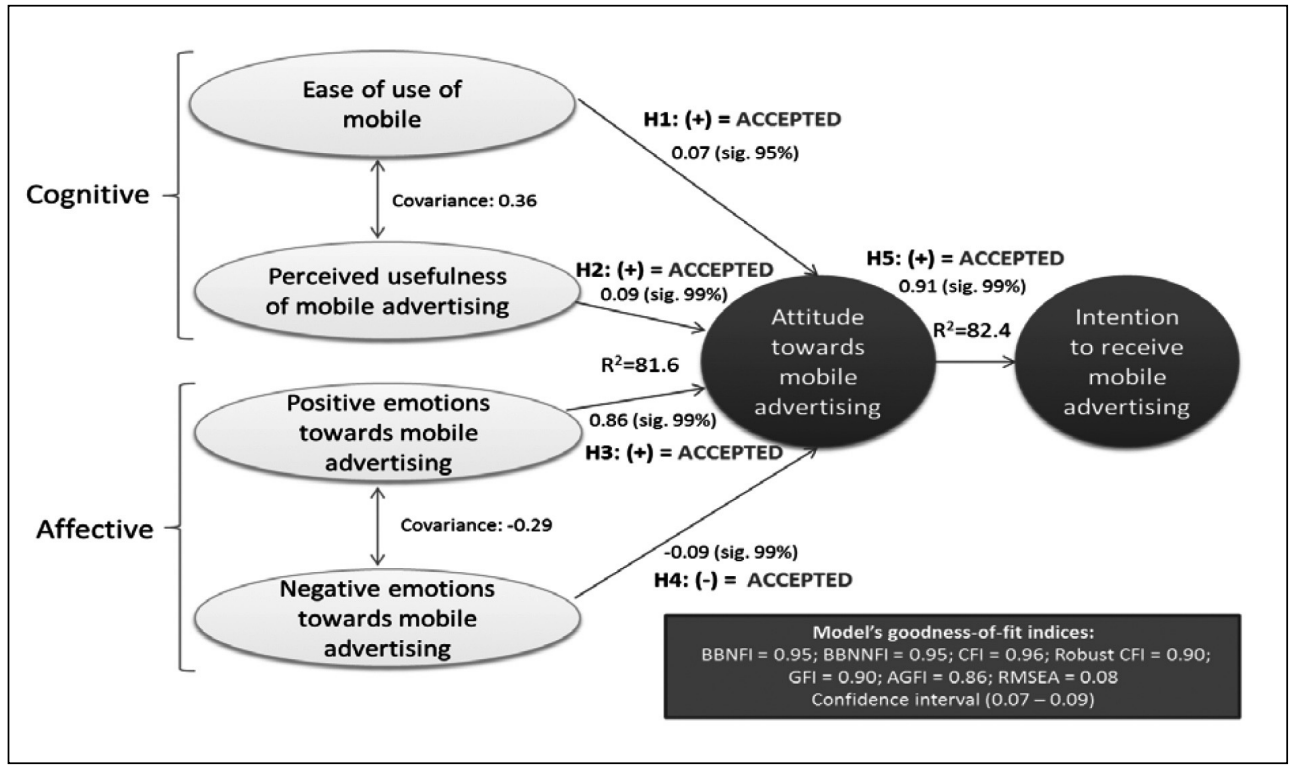

Source: own

Next, clusters of users were defined based on the influence exerted by the NRG on users' attitudes and behavioural intentions with regard to mobile advertising. To achieve this, we applied a sequential cluster analysis (hierarchical and then k-means clustering), and then validated the solution using the ANOVA test and discriminant analysis. The ANOVA results reflect the existence of inequality of means between the groups with a confidence interval of $99 \%$ in all variables. In the discriminant analysis, Wilks's lambda, with a $p$-value $<0.01$, allows us to accept the hypothesis of differences between the groups of users in the scores awarded to the independent variables. Box's M-test shows that the F-statistic is 32.56 , with a significance level of less than 0.001 , allowing us to reject the null hypothesis that the variance-covariance matrices show no statistically significant differences between the groups. Finally, the confusion matrix shows that $97.4 \%$ of the originally grouped cases were correctly classified. All of this confirms that the two clusters obtained are different and were correctly identified:

- GROUP 1. Users who are independent of their NRGs. These people are not influenced by their NRGs and are thus unlikely to imitate the people closest to them with regard to receiving mobile advertising (average score of 1.24 on a scale of 1 to 5 for this variable) or their behaviour towards it (1.26), to discuss the mobile advertising they receive with them (1.91) or to share the same opinion as the group about it (1.27). This group constituted $65.36 \%$ of the sample.

- GROUP 2. Users influenced by their reference groups. This group consists of people who are highly likely to imitate their NRG with regard to mobile advertising, specifically in terms of receiving it (3.33) and their behaviour towards it (3.13), their tendency to discuss it with the members of the group (3.68), and to share the same opinion of it with them (3.32). This cluster accounted for $34.64 \%$ of the sample.

Once the two groups had been defined, we applied the model to each one. Figure 4 shows the Path model for the independent and influenced users, as well as their nonstandardized parameter values, the results of the multi-sample analysis and their goodness of fit. We chose to show the values of the non- 


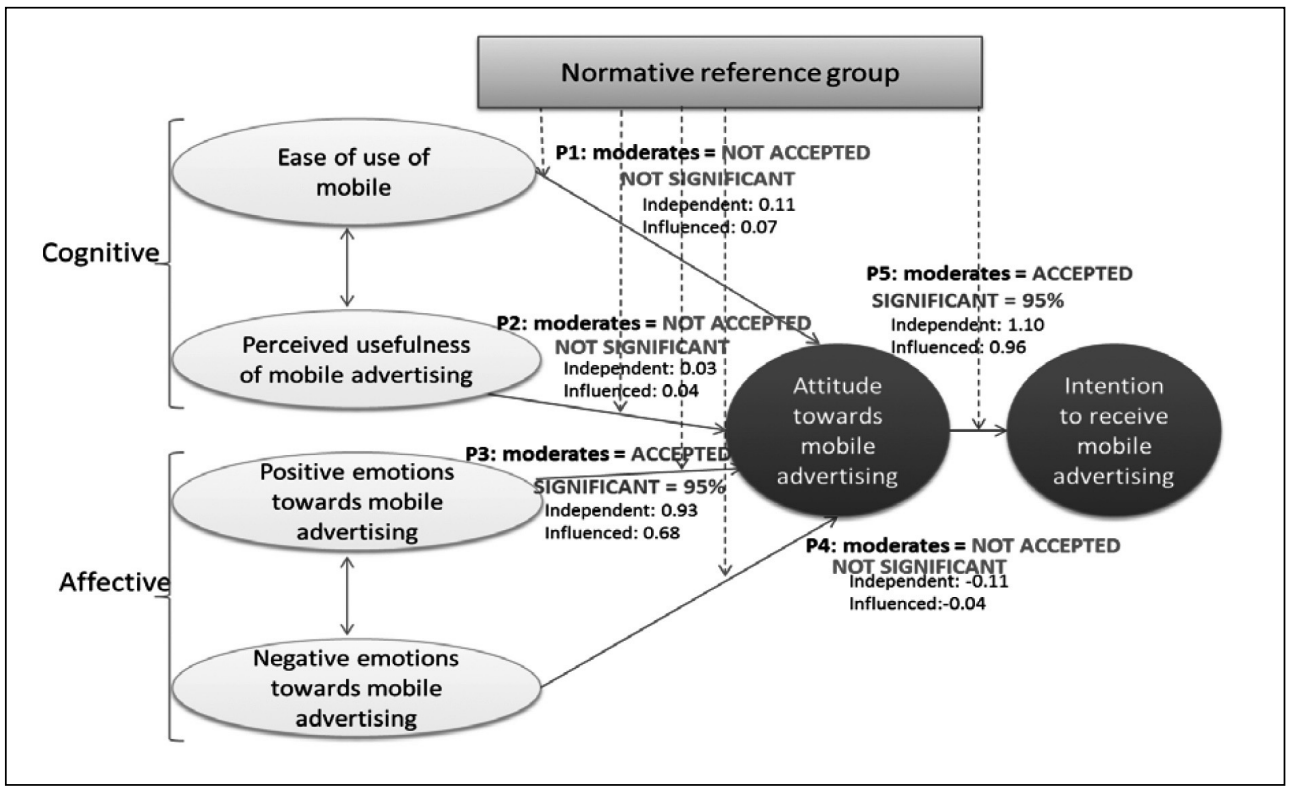

Source: own

standardized regression coefficients, as they better illuminate the differences between the groups (Jaccard \& Wan, 1996).

The chi-square difference test of the multi-sample analysis makes it possible to see whether the removal of the restriction on equality between the groups' parameters significantly improves the model and, therefore, if a model without equality in these parameters would be advisable. In our case, the model improved when the equality in the parameters of the relationships between the influence of positive emotions on attitude and the influence of attitude on the intention to receive mobile advertising was eliminated (Tab. 4).

Finally, Figure 5 shows the full model with both the accepted hypotheses and propositions and those we could not confirm.

\section{Tab. 4: Results of the comparison of the parameter values between the groups}

\begin{tabular}{l|r|r}
\multicolumn{1}{c|}{ Relationships } & $\begin{array}{c}\text { Chi-Square } \\
\text { Difference }\end{array}$ & \multicolumn{1}{c}{ Probability } \\
\hline Ease of use => Attitude towards mobile advertising & 0.01 & 0.973 \\
\hline Perceived usefulness => Attitude towards mobile advertising & 3.46 & 0.063 \\
\hline Positive emotions => Attitude towards mobile advertising & $\mathbf{4 . 9 4 ^ { \mathrm { a } }}$ & $\mathbf{0 . 0 2 6}$ \\
\hline Negative emotions => Attitude towards mobile advertising & 2.09 & 0.149 \\
\hline $\begin{array}{l}\text { Attitude towards mobile advertising => Intention to receive } \\
\text { mobile advertising }\end{array}$ & $\mathbf{4 . 5 5 ^ { \mathrm { a } }}$ & $\mathbf{0 . 0 3 3}$ \\
\hline
\end{tabular}




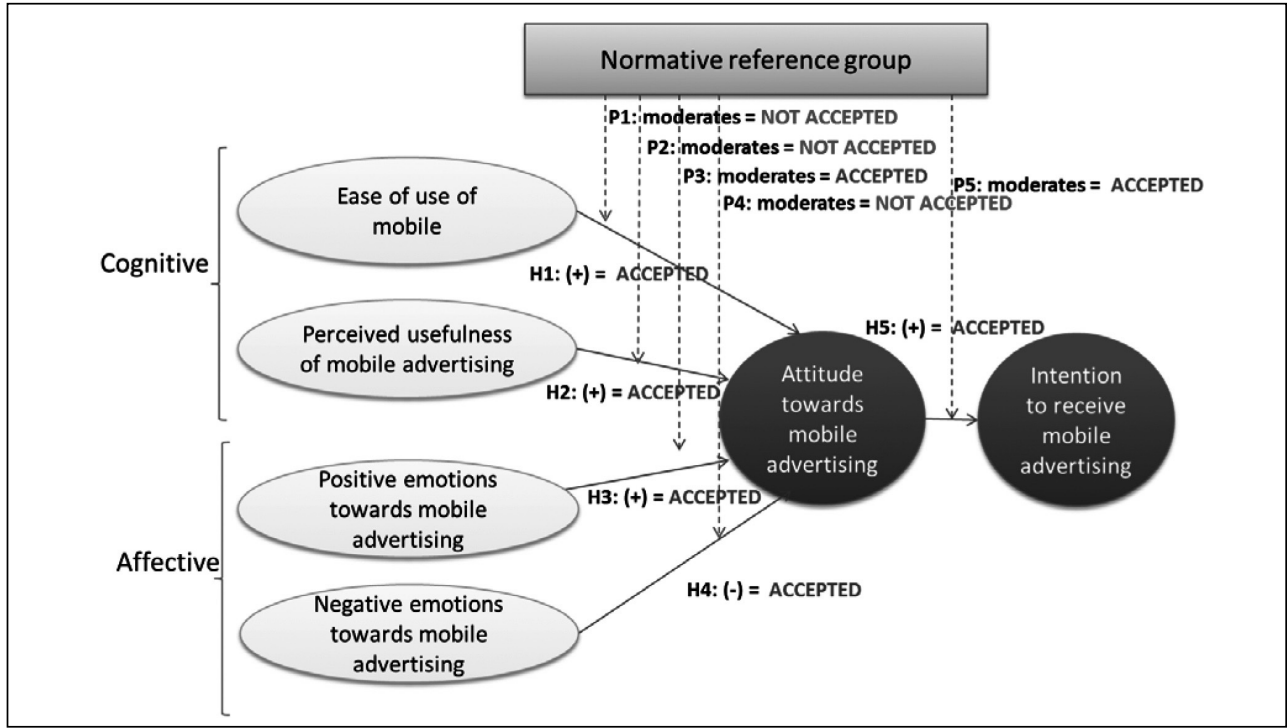

Source: own

\section{Conclusions}

As in other fields (Schwarz, 2000), our results confirm that both cognitive and affective factors should also be taken into account when examining attitudes towards mobile advertising (acceptance of $\mathrm{H} 1, \mathrm{H} 2, \mathrm{H} 3$ and $\mathrm{H} 4$ ). We accept the direct, positive influence of this attitude on the intention to receive mobile advertising (acceptance of $\mathrm{H} 5$ ), in keeping with the work of Tsang et al. (2004), Lee et al. (2006), SoroaKoury and Yang (2010), and Xu (2006).

In terms of cognitive factors, the easier it is for users to use their mobile phones, the more positive the attitude they develop towards receiving mobile advertising. Similarly, the greater the perceived usefulness of the mobile advertising, the more positive the attitude developed by users towards receiving it. In short, our results are in line with the ideas proposed by Karjaluoto et al. (2008) but contradict those laid out by Soroa-Loury and Yang (2010). At the same time, they represent an advance with regard to previous studies, which were limited to universes of young people and students and, crucially, referred only to text messages.

With regard to affective factors, the development of positive emotions in users generated as a result of having received mobile advertising leads to a positive attitude towards this means of communication. Moreover, it is worth noting that, in our model, these emotions are the variables that most affected the formation of attitudes towards mobile advertising. The strong effect of positive emotions on attitudes could be interpreted as two overlapping concepts. However, attitude is viewed as a broader concept, which includes emotion as an integral part of its formation (Bagozzi et al., 1999; Scherer, 2005), and, also, as an evaluative judgement rather than an affective state (Bagozzi et al., 1999; Cohen et al., 2008).

The development of negative emotions leads to more negative attitudes towards receiving mobile advertising. These findings support those reported by Park and Salvendy (2012) in their study of 48 students, although in our case the sample was far more representative.

To our surprise, the NRG was found to play a moderating role in two of the five established relationships (propositions $\mathrm{P} 1, \mathrm{P} 2$ and $\mathrm{P} 4$ could not be accepted, while propositions P3 and P5 could). Unlike in previous studies, we identified two user groups based on the influence exerted 
by their reference group with regard to mobile advertising: independent and influenced users. Among independent users, the positive emotions generated by mobile advertising have a greater influence on the development of a positive attitude towards receiving mobile advertising ( $\mathrm{P} 3$ is accepted). Also among independent users, a more intense positive relationship was found between the attitude towards mobile advertising and the intention to receive it (P5 is accepted). These are very interesting results, as we found that the weaker the influence of others' opinions on a subject, the stronger the relationships between attitudes towards mobile advertising and behavioural intention. The relationship between positive feelings and attitudes was also stronger among independent users.

Users who allow themselves to be influenced by their reference group try to fit into it. Therefore, the group's opinion can weaken the influence of these users' positive emotions on the formation of their attitude towards mobile advertising and of said attitude on their behavioural intention. Moreover, no differences were found between independent users and users influenced by their NRGs with regard to the formation of attitudes due to ease of use, perceived usefulness or negative emotions.

The results have several relevant implications for business managers. First, the results with regard to the cognitive dimension suggest that managers should provide more knowledge to mobile phone users, as it fosters more positive attitudes towards mobile advertising. In this regard, mobile apps should be developed that are easy to use and designed to maintain and strengthen the relationship with customers. Moreover, to reach segments that do not make extensive use of mobile apps, they should support the development of more user-friendly mobiles tailored to these specific segments.

A second recommendation for mobile advertisers is to engage in actions that increase the usefulness of receiving advertising via mobile, such as including a discount in a useful application for the recipient, including a suitable app (own or third-party) in the advertisement, or offering tangible or intangible rewards (e.g., additional memory on a virtual device) that can be claimed with a code obtained in the advertisement.

The third recommendation is related to emotions, as mobile advertising managers should seek to promote positive emotions in order to foster a positive attitude towards this channel and prevent the production of negative emotions (above all, the sensation of having been deceived). Chances are, if you own a smartphone, you have received or seen an advertising message based on humour or sex on your mobile device. Some mobile advertisements even manage to infiltrate their audiences' mobiles' files (galleries), slipping in amongst their personal photos. Advertisements should seek to generate positive emotions, such as pleasure, interest, entertainment and interaction, that are at once credible and motivating. Pleasure can be achieved with images (colour and movement), sound (evocative melodies), and text (credible, memorable slogans). Audiences' interest can be piqued, for example, by using celebrities. Recurring humorous or erotic themes can be used in advertisements to entertain.

It is important to stress the need for credibility and to ensure that promises are kept, that mobile advertisements are truthful. Otherwise, they can generate negative emotions.

The fact that the model is more conducive to generating positive attitudes and behavioural intention among users who are independent from their NRGs gives rise to a fourth recommendation, namely, to carry out advertising campaigns aimed at taking advantage of this opportunity to reach these individuals, seeking their personalized enjoyment.

Additionally, users often have special relationships with their phones. In this regard, we conducted an experiment with our students in which they were asked to record a purchase with their smartphone. When they came to class, they were supposed to give their mobile to a classmate to listen to and evaluate the transaction. Much to our surprise, some students refused to hand over their phones. They would rather get a zero on the activity than share their phone. In short, some people have a very strong emotional tie to their mobile phone (Kolsaker \& Drakatos, 2009), which leads us to our fifth recommendation: to strengthen these emotional bonds with a view to increasing the effectiveness of mobile advertising. For example, iPhone users end their e-mails with the signature 'Sent from my iPhone', offering proof of their affective relationship with their phone. 
The sixth recommendation is for companies to carry out direct mobile marketing campaigns with those customers who give them their permission to do so. It is a medium that yields very good results and whose costs can be tailored to the financial possibilities of each company.

With regard to the limitations of this research, while we believe that the study sample was sufficient and representative, a larger sample size would have been desirable. Another key limitation was the lack of applied research in the literature on the moderating role of the subjective norm in the mobile advertising acceptance process, which required us to propose research propositions instead of hypotheses based on a robust theoretical framework.

Our study sought to determine how NRGs can moderate the effects of cognitive and affective dimensions on attitudes towards mobile advertising and on the moderating role played by such attitudes with regard to the intention to receive mobile advertising. As a future line of research, we propose studying the direct effects of the NRG on the set of variables not previously examined in the literature.

Because mobile marketing communications can take so many different forms, it would be interesting to apply the proposed model to the various types of advertising used by advertisers.

Finally, in keeping with the discussion of our results, a further necessary step in this research is to identify the factors affecting responses to mobile advertising when customers are not aware of having given permission to the advertiser to send it, for example, because they agreed to the conditions automatically upon signing the contract.

\section{References}

Ajzen, I. (1991). The theory of planned behavior. Organizational Behavior and Human Decision Processes, 50(2), 179-211. doi:10.1016/0749-5978(91)90020-T.

Anderson, J. C., \& Gerbing, D. W. (1988). Structural Equation Modeling in Practice: A Review and Recommended Two-Step Approach. Psychological Bulletin, 103(3), 411-423. doi:10.1037/0033-2909.103.3.411.

Bagozzi, R. P. (2000). On the concept of intentional social action in consumer behavior. Journal of Consumer Research, 27(3), 388-396. doi:10.1086/317593.
Bagozzi, R. P., Gopinath, M., \& Nyer, P. U. (1999). The role of emotions in marketing. Journal of the Academy of Marketing Science, 27(2), 184-206. doi:10.1177/0092070399272005.

Bagozzi, R. P., \& Yi, Y. (1988). On the evaluation of structural equation models. Journal of the Academy of Marketing Science, 16(1), 74-94. doi:10.1007/BF02723327.

Bamba, F., \& Barnes, S. J. (2007). SMS advertising, permission and the consumer: A study. Business Process Management Journal, 13(6), 815-829. doi:10.1108/14637150710834578.

Barwise, P., \& Strong, C. (2002). Permissionbased mobile advertising. Journal of Interactive Marketing, 16(1), 14-24. doi:10.1002/dir.10000.

Bauer, H. H., Barnes, S. J., Reichardt, T., \& Neumann, M. M. (2005). Driving consumer acceptance of mobile marketing: A theoretical framework and empirical study. Journal of Electronic Commerce Research, 6(3), 181-192.

Boehner, K., DePaula, R., Dourish, P., \& Sengers, P. (2007). How emotion is made and measured. International Journal of Human Computer Studies, 65(4), 275-291. doi:10.1016/j.ijhcs.2006.11.016.

Carroll, A., Barnes, S., \& Scornavacca, E. (2005). Consumers perceptions and attitudes towards SMS mobile marketing in New Zealand. In W. Brookes, E. Lawrence, R. Steele, \& E. Chang (Eds.), International Conference on Mobile Business. ICMB 2005. Los Alamitos, CA: IEEE Computer Society. doi:10.1109/ICMB.2005.30.

Childers, T., \& Rao, A. (1992). The Influence of Familial and Peer-Based Reference Groups on Consumer Decisions. Journal of Consumer Research, 19(2), 198-211. doi:10.1086/209296.

Choi, Y. K., Hwang, J.-S., \& McMillan, S. J. (2008). Gearing up for mobile advertising: A cross-cultural examination of key factors that drive mobile messages home to consumers. Psychology and Marketing, 25(8), 756-768. doi:10.1002/mar.20237.

Cohen, J. B., Pham, M. T., \& Andrade, E. B. (2008). The nature and role of affect in consumer behavior. Handbook of Consumer Psychology, 297-348.

Davis, F. D. (1989). Perceived usefulness, perceived ease of use, and user acceptance of information technology. MIS Quarterly: Management Information Systems, 13(3), 319339. doi: $10.2307 / 249008$.

Dean, M., Raats, M. M., \& Shepherd, R. (2008). Moral concerns and consumer choice of 
fresh and processed organic foods. Journal of Applied Social Psychology, 38(8), 2088-2107. doi:10.1111/j.1559-1816.2008.00382.x.

Fishbein, M., \& Ajzen, I. (1975). Belief, attitude, intention and behavior: An introduction to theory and research. Reading, MA: AddisonWesley.

Fitzgerald, J. L., \& Arndt, S. (2002). Reference group influence on adolescent alcohol use. Journal of Alcohol and Drug Education, 47(2), 42-56.

Hair, J. F., Anderson, R., Tatham, R., \& Blanck, W. (1999). Análisis multivariante (5th ed.). Madrid: Prentice Hall Iberia.

IAB Spain Research. (2012). IV Estudio IAB Spain sobre Mobile Marketing: Informe de Resultados. Retrieved from http://www.iabspain. net/wp-content/uploads/downloads/2012/09/ IV-Estudio-IAB-Spain-sobre-Mobile-MarketingVersi\%C3\%B3n-Completa.pdf.

Infoadex. (2014). Estudio Infoadex de la inversión publicitaria en España 2014. Madrid: Infoadex.

Jaccard, J., \& Wan, C. K. (1996). LISREL approaches to interaction effects in multiple regression. Sage.

Jayawardhena, C., Kuckertz,A., Karjaluoto, H., \& Kautonen, T. (2009). Antecedents to permission based mobile marketing: An initial examination. European Journal of Marketing, 43(3-4), 473-499. doi:10.1108/03090560910935541.

Karjaluoto, H., Lehto, H., Leppäniemi, M., \& Jayawardhena, C. (2008). Exploring gender influence on customer's intention to engage permission-based mobile marketing. Electronic Markets, 18(3), 242-259.

Khalifa, M., \& Shen, K. N. (2008). Explaining the adoption of transactional B2C mobile commerce. Journal of Enterprise Information Management, 21(2), 110-124. doi:10.1108/17410390810851372.

Kolsaker, A., \& Drakatos, N. (2009). Mobile advertising: The influence of emotional attachment to mobile devices on consumer receptiveness. Journal of Marketing Communications, 15(4), 267-280. doi:10.1080/13527260802479664.

Lee, S.-F., Tsai, Y.-C., \& Jih, W.-J. (2006). An empirical examination of customer perceptions of mobile advertising. Information Resources Management Journal, 19(4), 39-55. doi:10.4018/irmj.2006100103.

Lerner, J. S., Han, S., \& Keltner, D. (2007). Feelings and consumer decision making:
Extending the appraisal-tendency framework. Journal of Consumer Psychology, 17(3), 184-187. doi:10.1016/S1057-7408(07)70023-2.

Levav, J., \& McGraw, A. P. (2009). Emotional accounting: How feelings about money influence consumer choice. Journal of Marketing Research, 46(1), 66-80. doi:10.1509/ jmkr.46.1.66.

López-Nicolás, C., Molina-Castillo, F., \& Bouwman, H. (2008). An assessment of advanced mobile services acceptance: Contributions from TAM and diffusion theory models. Information and Management, 45(6), 359-364. doi:10.1016/j.im.2008.05.001.

Lu, J., Yao, J. E., \& Yu, C.-S. (2005). Personal innovativeness, social influences and adoption of wireless Internet services via mobile technology. Journal of Strategic Information Systems, 14(3), 245-268. doi:10.1016/j. jsis.2005.07.003.

MacKenzie, S. B., Podsakoff, P. M., \& Jarvis, C. B. (2005). The problem of measurement model misspecification in behavioral and organizational research and some recommended solutions. Journal of Applied Psychology, 90(4), 710-730. doi:10.1037/0021-9010.90.4.710.

Mano, H. (2004). Emotion and consumption: Perspectives and issues. Motivation and Emotion, 28(1), 107-120. doi:10.1023/B:MOEM.0000027280.10731.76.

Miguel-Dávila, J.-A., López, D., \& De PablosHeredero, C. (2012). Open business models in systemic contexts: The case of the mobile phone industry. Universia Business Review, 36, 48-62.

MMA Mobile Marketing Association. (2012). $5^{\circ}$ Estudio de Inversión en Marketing y Publicidad Móvil España. Spain: Mobile Marketing Association.

Muk, A., \& Babin, B. J. (2006). US consumers' adoption-non-adoption of mobile SMS advertising. International Journal of Mobile Marketing, 1(1), 21-29.

Okazaki, S., Katsukura, A., \& Nishiyama, M. (2007). How mobile advertising works: The role of trust in improving attitudes and recall. Journal of Advertising Research, 47(2), 165178. doi:10.2501/S0021849907070195.

O'Neill, R. M., \& Lambert, D. R. (2001). The emotional side of price. Psychology and Marketing, 18(3), 217-237. doi:10.1002/1520-6793(200103)18:3<217::AIDMAR1006>3.0.CO;2-M.

Park, T., \& Salvendy, G. (2012). Emotional Factors in Advertising Via Mobile Phones. 
International Journal of Human-Computer Interaction, 28(9), 597-612. doi:10.1080/10447 318.2011.641899.

Peter, J., \& Olson, J. (2005). Consumer behaviour and marketing strategy. UK: McGraw-Hill.

Rohm, A. J., \& Sultan, F. (2006). An exploratory cross-market study of mobile marketing acceptance. International Journal of Mobile Marketing, 1(1), 4-12.

Russell, J. A. (2003). Core Affect and the Psychological Construction of Emotion. Psychological Review, 110(1), 145-172. doi:10.1037//0033-295X.110.1.145.

Scherer, K. R. (2001). Emotions, Psychological Structure of. In N. J. Smelser, \& P. B. Baltes (Eds.), International Encyclopedia of the Social and Behavioral Sciences. (pp. 4472-4477). Oxford: Pergamon.

Scherer, K. R. (2005). What are emotions? And how can they be measured? Social Science Information, 44(4), 695-729. doi:10.1177/0539018405058216.

Schwarz, N. (2000). Emotion, cognition, and decision making. Cognition and Emotion, 14(4), 433-440. doi:10.1080/026999300402745.

Soroa-Koury, S., \& Yang, K. C. C. (2010). Factors affecting consumers' responses to mobile advertising from a social norm theoretical perspective. Telematics and Informatics, 27(1), 103-113. doi:10.1016/j.tele.2009.06.001.

Tsang, M. M., Ho, S.-C., \& Liang, T.-P. (2004). Consumer attitudes toward mobile advertising: An empirical study. International Journal of Electronic Commerce, 8(3), 65-78.

van Waterschoot, W., Kumar Sinha, P., Van Kenhove, P., \& De Wulf, K. (2008). Consumer learning and its impact on store format selection. Journal of Retailing and Consumer Services, 15(3), 194-210. doi:10.1016/j. jretconser.2007.03.005.

Venkatesh, V., \& Davis, F. D. (2000). Theoretical extension of the Technology Acceptance Model: Four longitudinal field studies. Management Science, 46(2), 186-204. doi:10.1287/mnsc.46.2.186.11926.

Vincent, J. (2005). Emotional attachment and mobile phones. In P. Glotz, S. Bertschi, \& C. Locke (Eds.), Thumb Culture. The Meaning of Mobile Phones for Society (pp. 95-104). Bielefeld: Transcript.
White, C., \& Yu, Y. (2005). Satisfaction emotions and consumer behavioral intentions. Journal of Services Marketing, 19(6), 411-420. doi:10.1108/08876040510620184.

$\mathrm{Xu}$, D. J. (2006). The influence of personalization in affecting consumer attitudes toward mobile advertising in China. Journal of Computer Information Systems, 47(2), 9-19.

Xu, D. J., Liao, S. S., \& Li, Q. (2008). Combining empirical experimentation and modeling techniques: $A$ design research approach for personalized mobile advertising applications. Decision Support Systems, 44(3), 710-724. doi:10.1016/j.dss.2007.10.002.

Yang, B., Kim, Y., \& Yoo, C. (2013). The integrated mobile advertising model: The effects of technology- and emotion-based evaluations. Journal of Business Research, 66(9), 13451352. doi:10.1016/j.jbusres.2012.02.035.

Zhang, J., \& Mao, E. (2008). Understanding the acceptance of mobile SMS advertising among young Chinese consumers. Psychology and Marketing, 25(8), 787-805. doi:10.1002/ mar.20239.

Zielke, S. (2011). Integrating emotions in the analysis of retail price images. Psychology and Marketing, 28(4), 330-359. doi:10.1002/ mar.20355.

Cristina Olarte-Pascual, Ph.D. Professor Universidad de La Rioja Facultad de Ciencias Empresariales Department of Business Administration cristina.olarte@unirioja.es

Prof. Jorge Pelegrín-Borondo, Ph.D. Professor Universidad de La Rioja Facultad de Ciencias Empresariales Department of Business Administration jorge.pelegrin@unirioja.es

Prof. Eva Reinares-Lara, Ph.D. Professor Universidad Rey Juan Carlos Facultad de Ciencias Jurídicas y Sociales Department of Business Administration eva.reinares@urjc.es 


\section{Abstract}

\section{COGNITIVE-AFFECTIVE MODEL OF ACCEPTANCE OF MOBILE PHONE ADVERTISING}

\section{Cristina Olarte-Pascual, Jorge Pelegrín-Borondo, Eva Reinares-Lara}

There are high expectations for mobile phone marketing and mobile advertising. In various European markets, such as the United Kingdom, Spain and Italy, mobile marketing campaigns have registered response rates of up to $47 \%$ among their target audience.

The main aim of this paper is to validate a cognitive-affective model of acceptance of mobile phone advertising that integrates the utilitarian perspective through the technology acceptance model, the affective dimension through emotions, and the moderating role of the normative reference group (NRG). This model was tested with structural equation modelling in a sample of 612 individuals ( $R^{2}$ of $82.4 \%$ ). To analyse the moderating effect of the NRG, a sequential cluster analysis was applied, generating two groups of users: independent and influenced. A multi-sample analysis was then performed.

The results showed the advisability of considering attitudes towards mobile advertising to be a variable shaped by conceptually complementary cognitive (perceived usefulness and perceived ease of use) and affective dimensions (positive emotions and negative emotions). Positive emotions had the strongest effect on the formation of this attitude. Negative emotions and cognitive dimensions had a few effect for the acceptance of mobile advertising. With regard to the moderating role of the NRG, among independent users, positive emotions affected the attitude more intensely and a stronger positive relationship was found between this attitude and the intention to receive advertising. No differences were found between independent users and users influenced by their NRGs with regard to the formation of attitudes due to ease of use, perceived usefulness or negative emotions. The paper thus provides a comprehensive analysis of the acceptance of mobile advertising that integrates both cognitive-affective views and the moderating role of the NRG with implications for management.

Key Words: Mobile advertising, attitudes, perceived usefulness, ease of use, reference group, emotions.

JEL Classification: M3.

DOI: 10.15240/tul/001/2016-4-010 